or as absolute values at 12 weeks, showed a surprising lack of correlation with long term survival.

This study does, however, have some important limitations. The most obvious is that the sample size is too small to support reliable conclusions about the relative importance of the different markers considered, particularly given the variability of marker measurements. A second limitation is that all patients were treated with zidovudine, preventing direct assessment of the degree to which marker changes were therapeutically induced. Thirdly, these results may not apply at all to drugs that have different mechanisms of action. None the less, these data do begin to suggest that for zidovudine or similar drugs biological markers may be useful in establishing therapeutic efficacy.

Additional investigations of this sort are urgently needed. Particularly important will be analyses on the ever growing bodies of data from completed clinical trials, especially those trials with placebo controls. Careful examination of larger data sets will be needed to confirm the general principle suggested here-that marker values can serve as meaningful end points in drug trials - and to clarify the roles of the various markers that have been studied.

SUSAN S ELLENBERG

Chief, Biostatistics Research Branch,

Division of AIDS, National Institute of Allergy and Infectious Diseases,

Bethesda, Maryland 20892, United States

1 Wittes J, Lakatos E, Probstfield J. Surrogate endpoints in clinical trials: cardiovascular diseases. Stat Med 1989;8:415-26.

2 Ellenberg SS, Hamilton JM. Surrogate endpoints in clinical trials: cancer. Stat Med 1989;8:405-14

3 Hillis A, Seigel D. Surrogate endpoints in clinical trials: ophthalmologic disorders. Stat Med $1989 ; 8: 427-30$.

4 Volberding PA, Lagakos SW, Koch MA, et al. Zidovudine in asymptomatic human immunodeficiency virus infection. N Engl f Med 1990;322:941-9.

5 Fischl MA, Richman DD, Hansen N, et al. The safety and efficacy of zidovudine (AZT) in the treatment of subjects with mildly symptomatic human immunodeficiency virus type 1 (HIV) infection. Ann Intern .Med 1990;112:727-37.

6 Weiss R, Mazade L, eds. Surrogate endpoints in evaluating the effectiveness of drugs against HIV infection and AIDS. Washington, DC: National Academy Press, 1990. (Institute of Medicine, September $11-121989$ conference summary $)$

7 Machado SG, Gail MH, Ellenberg SS. On the use of laboratory markers as surrogates for clinical endpoints in the evaluation of treatment for HIV infection. $\mathcal{F}$ Acquir Immune Defic Syndr 1990;3:1065-73.

8 The Cardiac Arrhythmia Suppression Trial (CAST) Investigators. Preliminary report: effect of encainide and flecainide on mortality in a randomized trial of arrhythmia suppression after myocardial infarction. N Engl f Med 1989;321:406-12.

9 Jacobson MA, Bacchetti P, Kolokathis A, et al. Surrogate markers for survival in patients with AIDS and AIDS related complex treated with zidovudine. BMF 1991;302:73-8.

\title{
"Taken from this place and hanged by the neck..."
}

\section{Reduction in prison suicides demands cultural change}

Just before Christmas the British parliament once again voted not to reintroduce the death penalty. But while this debate endlessly recurs, more and more prisoners are taking their own lives - almost always by hanging. ${ }^{1}$ It was in 1986 that the Home Office produced its last report on reducing suicides in prison, ${ }^{2}$ and it was in 1987 that suicides more than doubled (from 21 to 46 ). ${ }^{3}$ Clearly the strategy suggested was a failure because suicides have continued to run at roughly twice the number of the early '80s: 48 prisoners killed themselves in prisons in England and Wales in 1990. One response to the problem has been a second report on suicides from the chief inspector of prisons, ${ }^{3}$ and this one contains the seeds of a solution.

Stephen Tumim, a judge, is the second chief inspector, and he has had enormous impact in his short term. With his bow ties, love of art, and inability to drive he has something of the air of a well bred innocent. This manner fools many and may have fooled the Home Office apparatchiks into appointing a chief inspector whom they thought would be unlikely to cause trouble. But Tumim's blunt, well argued, detailed, and highly readable reports have begun to shake the Home Office out of its complacency. Margaret Thatcher is said to have read his report on integral sanitation (prisonspeak for toilets in cells) and been convinced by its argument when the Home Office was wavering. And the new Home Secretary, Kenneth Baker, is reported to have torn up his department's inadequate response to Tumim's latest report and made his bureaucrats start again. ${ }^{+}$The fact that the Home Office put out a new guide on suicide prevention a week before the publication of the chief inspector's report shows how nervous it was.

Suicide in prison is not a new problem. A Parkhurst doctor observed in 1913 that the suicide rate of prisoners was three times that of the general population, ${ }^{5}$ and Topp showed that suicides were commoner among prisoners in $1880(60 / 100000)$ than in $1970(40 / 100000) .{ }^{6}$ A 1990 review confirms, however, a steady increase from the early ' 70 s, and the rate is now higher $(90 / 100000)$ than in $1880 .^{1}$ Comparisons with rates in the general population are obviously fraught with difficulty, and high rates of suicide might be expected among socially disadvantaged young men, many of whom have mental health and drug problems, at a time when they have been convicted of a crime and had their liberty taken away.

The Home Office tends towards a complacent response with, for instance, its assertion after the report on suicides at Risley that "No prison establishment can guarantee that suicide will not occur. The process of incarceration and the mental state of a significant proportion of the inmate population makes such a guarantee impossible." The Home Secretary makes a similar point in the first paragraph of his response to the latest report, ${ }^{8}$ and later he points out that suicides among men under 25 outside custody increased by $20 \%$ between 1987 and 1988 . There will inevitably be some suicides in prison, but all this smacks of defensiveness.

The chief inspector notes this defensiveness when he comments on the prison department's guidelines on suicide prevention, which are primarily concerned with identifying those at risk of suicide and stopping them. The department's circulars are more of a bureaucratic than a human response to the problem. "There was," says the chief inspector, "an overwhelming suspicion that [the procedures] were too defensive. The Circular Instruction was felt to be much more effective at setting out formal procedures rather than in encouraging proper attitudes to inmates." The inadequacy of this response is made complete by the fact that "only a few establishments are able to fulfil both the spirit and the letter of the Circular Instruction." Resources are inadequate, and staff are too poorly trained.

Trying to screen out suicidal prisoners is in itself not enough. The literature review of suicide and self injury published by the Home Office last year points out that most researchers are sceptical about being able to predict suicides. ${ }^{9}$ It isn't easy even in the best conditions. An American psychiatrist concluded after a prospective study of 4800 patients in psychiatric hospitals that "Identification of particular persons who will commit suicide is not currently feasible, because of the low sensitivity and specificity of 
available procedures and the low base rate of this behaviour." 10 The chance of detection is not helped when some prison doctors screening new prisoners "did not even bother to look up when talking with them.",

The answer to suicides in prisons lies in completely changing the culture of prisons. As both the chief inspector and the Home Secretary agree, the problem is not simply a medical one. It is a social problem, and it is a problem for our whole society, not just those delegated to cope with prisoners. The high rate of suicide in British prisons is rooted in the appalling conditions of the prisons - three quarters of suicides occur in local and remand prisons, which contain a quarter of the prisoners and have by far the worst conditions. ${ }^{3}$ Most of the British people have some notion that our prisons are disgusting, but only the few who have experienced the stink and squalor at first hand can really understand: you need some idea of what it is like to have to defaecate in a pot in front of others, eat your breakfast in the same cell 15 hours after your supper and two hours before your lunch, and be afraid to go to sleep for fear of assault. The problem is that the initial shock passes. There tend to be two populations when it comes to prisons - those who have never known how bad the conditions are and those in whom the disgust has worn off. But it takes time to fade: a third of suicides occur in the first four weeks in custody. ${ }^{3}$

It is one of the achievements of Stephen Tumim that he has sustained the horror he experienced when he first entered prisons. Thus, although he makes 123 specific recommendations, ${ }^{3}$ he recognises that a reduction in suicides will come only with radical changes in our prisons. It will be important to train staff and improve living conditions, food, basic hygiene, clothing, education, employment, facilities for communication with friends and family, and medical services, but these changes will not be enough. What is needed is a change in the culture - the values, beliefs, language, and patterns of behaviour - of British prisons. The chief inspector quotes approvingly the governor of a local prison: "My own view is that the ethos of an establishment, how inmates are treated, will determine the amount of suicide and self injury. While I understand the need for form-filling and insurance policy type activity, it is not a substitute for investing in time spent with staff. Firstly, letting them know that it is part of the culture to demonstrate concern for inmates, and secondly, showing them ways of letting it show." Prison doctors might begin by letting prisoners sit down during admission consultations. $^{3}$

Changing culture is never easy and usually painful, and the culture of British prisons will probably change only if there is some change in British culture at large. Societies get the prisons they deserve. But one way to change prison culture will be to get rid of the monstrous local prisons and replace them with smaller community prisons. A recent leak suggests that this is what Lord Woolf and Stephen Tumim will advocate in their forthcoming report on the Strangeways riots. ${ }^{11}$

Executive editor, $B M \mathcal{F}$

RICHARD SMITH

1. Dooley E. Prison suicide in England and Wales, 1972-87. Br f Psychiatry 1990;156:40-5.

2 Working Group on Suicide Prevention. Report. London: Home Office, 1986.

3 Her Majesty's Chief Inspector of Prisons for England and Wales. Suicide and self harm in prison service establishments in England and Wales. London: HMSO, 1990.

4 Cohen N. Suicides blamed on state of jails. Independent 1990 Dec 20:1.

5 Goring C. The English convict. London: Darling, 1913.

6 Topp DO. Suicide in prison. Br F Psychiatry 1979;134:24-7.

Home Secretary. Response to the report of Her Majesty's Chief Inspector of Prison's report on Risley Remand Centre. London: Home Office, 1988.

8 Home Secretary. Response to the report of Her Majesty's Chief Inspector of Prison's report on suicide and self harm in prison service establishments in England and Wales. London: Home Office, 1990.

Lloyd C. Suicide and self-injury in prison: a literature review. London: HMSO, 1990. (Home Office research study 115.$)$

10 Pokorny A. Prediction of suicide in psychiatric patients: a report of a prospective study. Arch Gen Psychiatry 1983;40:249-57.

11 Carvel J. Woolf report to back local prisons and contracts. Guardian 1990 Dec 31:1.

\section{Treating children with spina bifida}

\section{An individual programme for each child}

Effective surgical treatment became possible for children with spina bifida with the development of a shunt system for hydrocephalus in the late 1950s. By the end of the 1960s the main complications of ventriculoatrial shunts, including ventriculitis and low grade staphylococcal septicaemia, had been described. ${ }^{1-3}$ The seriousness of the urinary tract problems was also being recognised and correlated with the neurological defects of the children. ${ }^{4}$

In 1971 Lorber published the results of the policy adopted in Sheffield of giving surgical treatment to all infants with meningomyelocele. His report described 524 unselected cases. ${ }^{5} \mathrm{He}$ concluded that there were four main criteria associated with a poor prognosis: severe hydrocephalus present at birth; a high level of paraplegia; congenital lumbar kyphosis; and associated congenital abnormalities or major birth injury. He showed that there was a high level of morbidity and resultant handicap in the children with more severe lesions.

Lorber's next report described a trial in which active treatment, including the use of antibiotics, was withheld from 25 infants with adverse criteria, while active treatment was given to 12 infants in whom no adverse criteria were present. ${ }^{6}$ All but two of the unoperated children died within six months, and the remainder within nine months.
These data had a profound effect on medical management in Britain, causing a swing of the pendulum away from advocating early treatment in all affected children towards selecting for treatment only those children who fulfilled the criteria for good prognosis. Some questioned how the survival rate of Lorber's unoperated cases could be considerably lower than had occurred 20 years previously and asked what other factors might be operative. ${ }^{78}$ The babies were being fed on demand but also being sedated. ${ }^{9}$ Nevertheless, selection became the standard policy.

Later, however, the issue was reopened. The spina bifida unit in Cardiff reviewed 49 children with spina bifida cystica, survivors of a group subject to selection for early surgery born in 1973-8, compared with 39 children alive from an earlier unselected series, born in the early $1960 \mathrm{~s} .{ }^{10}$ Sixteen children were also studied in whom the early decision not to operate had been reversed when the children survived. The authors concluded that emergency treatment was rarely necessary. The criteria being used for selection were not those related to mortality but rather to morbidity. It therefore made sense to select for early back closure those children who on established criteria were likely to be minimally handicapped. Children with more severe lesions could be treated more conservatively, allowing time for proper evaluation of the baby and discussion 